\title{
Evaluation of Serum Zinc Status and Glycated Hemoglobin of Type 2 Diabetes Mellitus Patients in a Tertiary Care Hospital of Assam
}

\section{Gautom Kumar Saharia, Rohini Kanta Goswami ${ }^{1}$}

Departments of Biochemistry, NEIGRIHMS, Shillong, Meghalaya, ${ }^{1}$ Assam Medical College and Hospital, Dibrugarh, Assam, India

Address for correspondence: Dr. Gautom Kumar Saharia, E-mail: gsaharia@yahoo.com

\section{ABSTRACT}

The present study was undertaken to find out any correlation between serum zinc concentration and $\mathrm{HbA} \mathrm{A}_{1 \mathrm{C}} \%$ in patients with type 2 diabetes mellitus (DM). The study was carried out on 50 newly diagnosed patients of type 2 diabetes and controls in the Department of Biochemistry, Assam Medical College and Hospital, Dibrugarh. Analyses of blood glucose (fasting and postprandial), glycated hemoglobin $\left(\mathrm{HbA}_{1 \mathrm{c}}\right)$, serum zinc, urea, and creatinine concentrations were performed by standard methods. Concentrations of fasting and postprandial blood glucose were significantly higher in the diabetic group than controls $(P<0.001)$ and the mean $\mathrm{HbA}_{1} \mathrm{c} \%$ was also higher in cases $(8.32 \% \pm 1.58 \%)$. The mean serum zinc concentration in cases was found to be significantly lower than controls (79.85 $\pm 13.4 \mathrm{vs} .109 .74 \pm 9.72 \mu \mathrm{g} / \mathrm{dL})$ and $P<0.001$ with correlation coefficient $r=-0.804$. Present study revealed an inverse relationship between $\mathrm{HbA}_{1 \mathrm{C}} \%$ and serum zinc concentration in patients with type $2 \mathrm{DM}$, substantiated by regression analysis.

Key words: Assam, serum zinc, $\mathrm{HbA}_{1 \mathrm{C}} \%$, type 2 diabetes mellitus

\section{INTRODUCTION}

iabetes mellitus (DM) is perhaps the major health problem in developing countries resulting in major morbidity for an individual in active period of his life. Although extensive research works have been undertaken throughout the globe to understand the details of the disease, yet many aspects of the disease are yet to be explored. With improvement of public health, mortality from infectious diseases has fallen dramatically. Yet paradoxically, a marked increase in prevalence of risk factors for noncommunicable diseases such as type 2 DM, cardiovascular diseases - hypertension, stroke, and cancer has occurred and they have become major

\begin{tabular}{|c|c|}
\hline \multicolumn{2}{|c|}{ Access this article online } \\
\hline Quick Response Code: & $\begin{array}{l}\text { Website: } \\
\text { www.jlponline.org }\end{array}$ \\
\hline 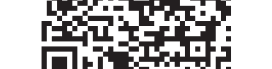 & $\begin{array}{l}\text { DOI: } \\
10.4103 / 0974-2727.115923\end{array}$ \\
\hline
\end{tabular}

contributors to morbidity and mortality. ${ }^{[1]}$ According to the data released by International Diabetes Federation in their $5^{\text {th }}$ edition of Diabetes Atlas, people living with diabetes is expected to rise from 366 million in 2011 to 552 million by 2030 which equates to three new cases every $10 \mathrm{~s}$ and 1 in 10 adults will be diabetic by 2030 . India is also no exception with 61.2 million cases in 2011 and estimated 101.2 million people with type 2 DM by 2030 if no intervention is done immediately.

It is seen that, zinc plays a clear role in the synthesis, storage, and secretion of insulin as well as conformational integrity of insulin. The decreased Zn, which affects the ability of the islet cells of pancreas to produce and secrete insulin, might also lead to the development of insulin resistance compounding the problem, particularly in type 2 diabetes. ${ }^{[2]}$ Studies by Rai et al., ${ }^{[3]}$ Tripathy et al., ${ }^{[4]}$ and $\mathrm{Oh}$ and Yoon ${ }^{[5]}$ have reported indices of zinc depletion in diabetes by demonstrating reduced levels of zinc in serum and other body fluids, but no such studies are available yet from this part of our country.

Journal of Laboratory Physicians / Jan-Jun 2013 / Vol-5 / Issue-1 
Diabetes affects zinc homeostasis in many ways, although it is most probably hyperglycemia, rather than any primary lesion related to diabetes, which is responsible for the decreases in total body zinc. So, monitoring blood glucose is an essential part of diabetes management and if one has to achieve the goal of preventing and delaying the complications, proper stress on monitoring becomes important. However, routinely used direct measurement of blood glucose level in patients has a limited value since it gives information only about the glucose concentration at the time of sampling and is influenced dramatically by diet. Nevertheless, an accurate index of a person's mean blood glucose level over a period of 6-8 weeks can be provided by measurement of specific type of glycated hemoglobin called the hemoglobin $\mathrm{A}_{1 \mathrm{C}}\left(\mathrm{HbA}_{1 \mathrm{C}}\right)$ concentration in blood. ${ }^{[6]}$ Hence, $\mathrm{HbA}_{1 \mathrm{C}} \%$ is one parameter which provides index of blood glucose control in cumulative sense. It is a reliable indicator of long-term hyperglycemia ${ }^{[7]}$ and the introduction of glycated hemoglobin as a monitor of long-term glucose control has helped in identifying those at risk of developing complications. So, we have undertaken this study with an aim to evaluate the serum zinc concentration in type $2 \mathrm{DM}$ patients of upper Assam and to find out any correlation between serum zinc concentration and $\mathrm{HbA}_{1 \mathrm{C}} \%$ in them.

\section{MATERIALS AND METHODS}

The present study was undertaken on newly diagnosed patients of type $2 \mathrm{DM}$ in the Department of Biochemistry and Advanced Clinical Biochemistry Laboratory, Assam Medical College and Hospital, Dibrugarh, Assam from September 2010 to August 2011. After obtaining approval from Institutional Human Ethics Committee, 50 patients were selected on the basis of clinical history, examination, and relevant investigations. All the cases were above 30 years of age and selected irrespective of sex and socioeconomic status. Equal numbers of age- and sex-matched voluntary healthy subjects were taken as controls. Patients receiving zinc supplementation or taking drugs which modify metabolism of zinc, patients taking oral hypoglycemic drugs or on insulin therapy, pregnant woman or persons suffering from chronic diseases were excluded from the study. Patients were considered to be diabetic on the basis of American Diabetic Association 2010 criteria for diagnosis of DM. ${ }^{[8]}$ Under all aseptic and antiseptic condition, $5 \mathrm{~mL}$ of blood sample was collected from each subject from a suitable peripheral vein (preferably antecubital vein) by venepuncture using a sterile disposable syringe and divided into a sterile empty vial, Fluoride vial and an EDTA vial. Fluoride vials were used for Glucose estimation and EDTA vials were used for estimation of glycated hemoglobin. Different parameters were estimation on Merck Microlab 300 Semi automated analyzer. All the reagent kits used were manufactured by Coral Clinical Systems. Serum Zinc was estimated by colorimetric method, ${ }^{[0,10]}$ glycated haemoglobin by ion exchange resin method, ${ }^{[7,11,12]}$ blood glucose (fasting and postprandial) by Glucose oxidase/Peroxidase method, ${ }^{[13,14]}$ blood urea by modified Berthelot method, ${ }^{[15,16]}$ and Sr. creatinine by alkaline picrate method. ${ }^{[17,18]}$ Statistical analysis of the data was performed by using Microsoft Excel software. A ' $P$ ' value of less than or equal to 0.05 was considered significant. Correlation was found out in SPSS by using regression equation.

\section{RESULTS AND DISCUSSION}

In our study, out of the 50 cases, 35 were males and 15 were females. Age distribution of the study subjects is shown in Table 1. It was observed that the mean fasting blood glucose and postprandial blood glucose in newly diagnosed type $2 \mathrm{DM}$ cases were found to be very significantly higher than that of the controls with $P<0.001$ as shown in Figure 1. In the present study, it is observed that the mean serum zinc concentration in newly diagnosed male type 2 DM cases has been $80.83 \pm 13.1 \mu \mathrm{g} / \mathrm{dL}$ and that in female cases, $77.56 \pm 14.2 \mu \mathrm{g} / \mathrm{dL}$. Here, the difference between male and female cases is very minimal and statistically not significant $(P>0.05)$. Similar results were also obtained by Kinlaw et al., ${ }^{[19]}$ and Zalewski $P$ et al. ${ }^{[20]}$ Williams et al., ${ }^{[21]}$ in their study, found no significant difference in serum zinc concentration between male and female cases.

It is also observed in the present study that the mean serum zinc concentration of the 50 cases is $79.85 \pm 13.4 \mu \mathrm{g} / \mathrm{dL}$ and that in controls is $109.74 \pm 9.72 \mu \mathrm{g} / \mathrm{dL}$ [Figure 2]. Hence, the serum zinc concentration in cases is lower than the concentration in controls and it is statistically highly significant $(P<0.001)$.

This is in accordance with McNair et al., ${ }^{[22]}$ who reported a definite hypozincemia in $39.7 \%$ of the patients. Serum zinc correlated inversely with the glycemic status of the cases and $P$ value is less than 0.005 in that study. Garg et al., ${ }^{[23]}$ also reported hypozincemia in DM. Williams et al., ${ }^{[21]}$ reported DM to be a condition most frequently associated with hypozincemia, where they observed $17 \%$ decrease in serum zinc concentration in diabetics, compared with controls $(P<0.0001)$. 
Table 2 shows that the mean $\mathrm{HbA}_{1 \mathrm{C}} \%$ of the 50 cases is $8.32 \% \pm 1.58 \%$ and that in controls is $4.72 \% \pm 0.78 \%$. Hence, the $\mathrm{HbA}_{1 \mathrm{C}} \%$ in cases is higher than the concentration in controls and it is statistically highly significant $(P<0.001)$. This finding is almost consistent with Trivelli et al., ${ }^{[11]}$ who observed that mean values for the proportions of fast hemoglobin components or glycohemoglobin in diabetes showed a nearly two-fold increase over values found in normal subjects. Similar findings were reported by Nathan et al., ${ }^{[7]}$ Diabetes Control and Complications Trial Research Group in 1993, ${ }^{[24]}$ United Kingdom Prospective Diabetes Study (UKPDS), ${ }^{[25]}$ Khaw $^{[26]}$ and Verma ${ }^{[27]}$ which strongly establishes the role of $\mathrm{HbA}_{1 \mathrm{C}}$ in type $2 \mathrm{DM}$.

In the present study, it is observed that the mean $\mathrm{HbA}_{1 \mathrm{C}}$ concentration in newly diagnosed type $2 \mathrm{DM}$ cases have an inverse relation with serum zinc concentration. From Figure 3, it is evident that the cases having lower values of $\mathrm{HbA}_{1 \mathrm{C}}$ have higher values of serum zinc concentration and vice versa. The Pearson correlation coefficient ' $r$ ' is found to be -0.804 which also establishes the strong negative correlation between these two parameters. Rai et al. ${ }^{[3]}$ showed that serum zinc concentrations were lower in diabetics as compared to controls and found a negative correlation with the glycated proteins in blood. Tripathy et al., ${ }^{[4]}$ found a significant negative correlations between serum $\mathrm{Zn}$ and $\mathrm{HbA1C} \%$ with ' $r$ ' value of -0.408 and diabetic subjects of the study were also found to have lower levels of $\mathrm{Zn}$ in serum as compared with healthy controls.

The findings of the present study are consistent with Reefat et al., ${ }^{[28]}$ who showed significant negative correlation between serum zinc concentration and

\begin{tabular}{lccccc}
\hline \multicolumn{3}{l}{ Table 1: Age distribution of cases and controls } \\
\cline { 2 - 3 } \cline { 5 - 6 } $\begin{array}{l}\text { Age group } \\
\text { (in years) }\end{array}$ & \multicolumn{3}{c}{ Cases } & & \multicolumn{2}{c}{ Controls } \\
\hline $31-40$ & 10 & 20.00 & & 10 & 20.00 \\
$41-50^{*}$ & 20 & 40.00 & & 20 & 40.00 \\
$51-60$ & 12 & 24.00 & & 12 & 24.00 \\
$61-70$ & 6 & 12.00 & & 6 & 12.00 \\
71 and above & 2 & 4.00 & & 2 & 4.00 \\
Total & 50 & 100.00 & & 50 & 100.00 \\
\hline
\end{tabular}

*Maximum no. of newly diagnosed cases in the age group 41-50 years

\section{Table 2: The range, mean, and standard deviation of $\mathrm{HbA}_{1 \mathrm{c}} \%$ in study subjects}

\begin{tabular}{|c|c|c|c|c|c|}
\hline \multirow{3}{*}{$\begin{array}{l}\text { Study } \\
\text { group }\end{array}$} & \multicolumn{5}{|c|}{$\mathrm{HbA}_{1 \mathrm{c}}(\%)$} \\
\hline & \multicolumn{2}{|c|}{ Range } & \multicolumn{3}{|c|}{ Mean $\pm S D$} \\
\hline & Male & Female & Male & Female & Overall \\
\hline Cases & $6.13-12.84$ & $7.15-14.40$ & $8.11 \pm 1.46$ & $8.79 \pm 1.81$ & $8.32 \pm 1.5^{*}$ \\
\hline Controls & $3.02-5.89$ & $3.54-6.14$ & $4.61 \pm 0.77$ & $4.97 \pm 0.75$ & $4.72 \pm 0.78$ \\
\hline
\end{tabular}

baseline $\mathrm{HbA} 1 \mathrm{c} \%$ value in the diabetic group and found correlation coefficient ' $r$ ' to be -0.33 . Oh and Yoon ${ }^{[5]}$ also reported similar findings in their study of zinc supplementation in glycemic control of type 2 diabetic patients. Marchesini et al., ${ }^{[2]}$ explained hypozincemia seen

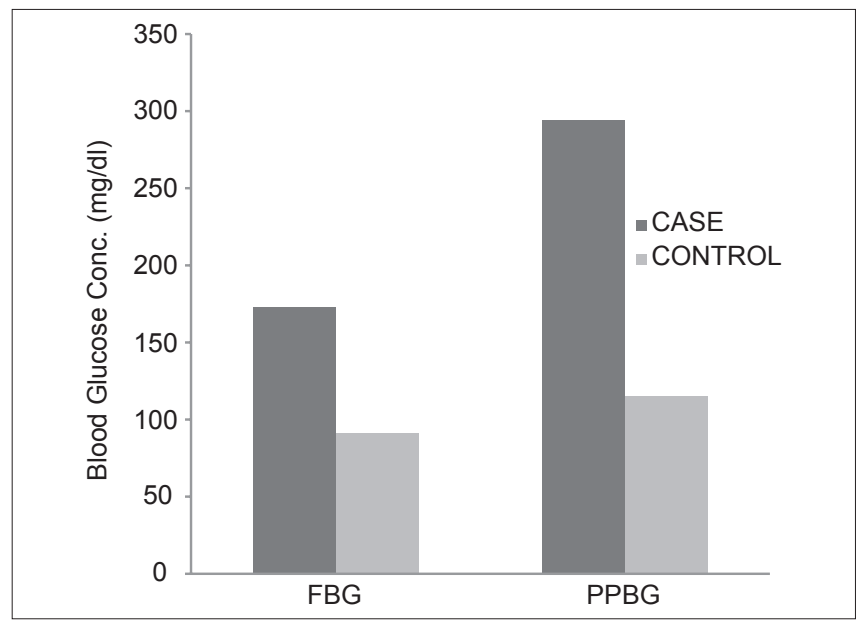

Figure 1: Mean fasting and PP blood glucose in study subjects

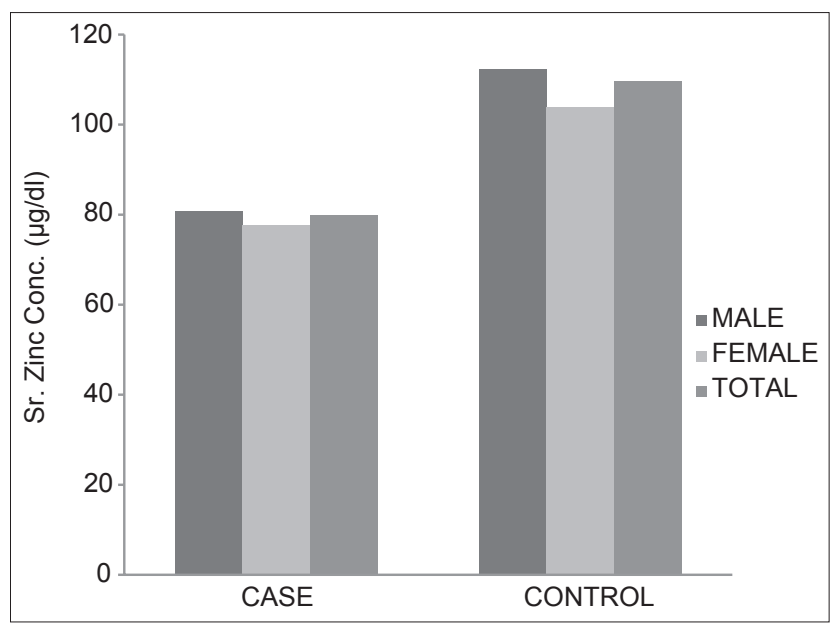

Figure 2: Mean serum zinc concentration in study subjects

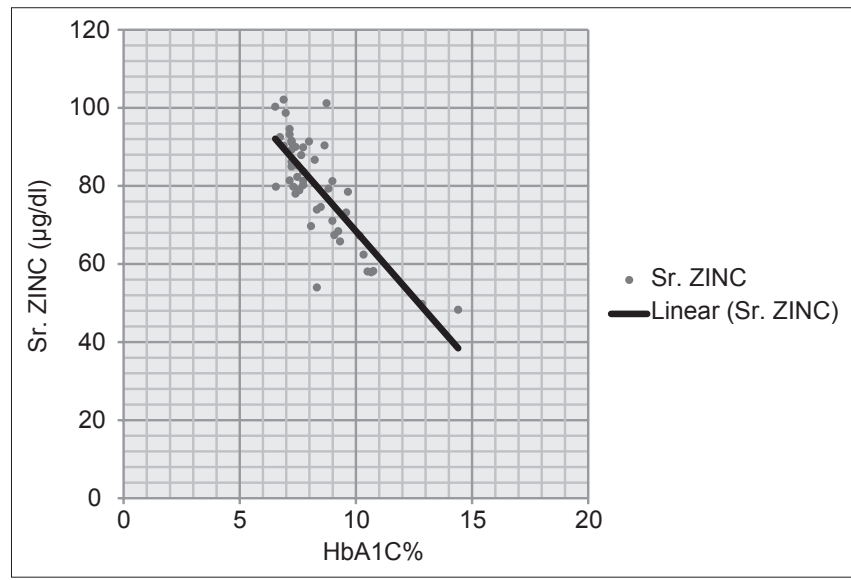

Figure 3: Correlation between glycated hemoglobin $(\mathrm{HbA} 1 \mathrm{c}) \%$ and serum zinc concentration in cases

Journal of Laboratory Physicians / Jan-Jun 2013 / Vol-5 / Issue-1 
in the diabetic population due to the low gastrointestinal absorption and high urinary excretion of zinc in diabetic patients.

When we have done regression analysis by taking $y=\mathrm{HbA} 1 \mathrm{C} \%$ and $x=$ Conc. of Sr. Zinc in the equation, $y=\mathrm{a}+\mathrm{bx}$, it reveals that $a=15.916$ and $b=(-0.095)$ and the equation becomes,

$\mathrm{HbA}_{1 \mathrm{C}} \%=15.916-0.095 \times$ Conc. of Sr. Zinc

So, $\mathrm{HbA}_{1 \mathrm{C}} \%$ can also be calculated from the value of serum zinc concentration.

In view of the above, it may be concluded that there is significant reduction of serum zinc in type $2 \mathrm{DM}$ patients although it is still not clear which came first: The effects of $\mathrm{DM}$ and hyperglycemia on zinc metabolism or the effects that follow alterations in $\mathrm{Zn}$ homeostasis on carbohydrate metabolism. There is evidence that hyperglycemia interferes with the active transport of $\mathrm{Zn}$ back into the renal tubular cells leading to hyperzincuria. Moreover, $\mathrm{Zn}$ also increases insulin sensitivity by increasing the binding ability of insulin to its receptors. ${ }^{[2]}$ So, it is a combination of multiple and interacting effects.

Our data suggest that in this study population of upper Assam, the serum $\mathrm{Zn}$ concentration is decreased and it would be interesting, in subsequent studies, to see the effectiveness of any intervention undertaken in this population of the easternmost part of the country.

\section{REFERENCES}

1. Zimmet P, Alberti KG, Shaw J. Global and Societal Implication of the Diabetes Epidemic. Nature 2001;414:782-7.

2. Chausmer AB. Zinc, insulin and diabetes. J Am Coll Nutr 1998;17:109-115.

3. Rai V, Iyer U, Mani I, Mani UV. Serum Biochemical changes in Insulin Dependent and Noninsulin Dependent Diabetes Mellitus and their role in the Development of Secondary Complications. Int J Diabetes Dev Ctries 1997;17:33-7.

4. Tripathy S, Sumathi S, Bhupal Raj G. Minerals Nutritional Status of Type 2 Diabetic Subjects. Int J Diabetes Dev Ctries 2004;24:27-8.

5. Hyun-Mee Oh, Jin-Sook Yoon. Glycemic control of type 2 diabetic patients after short-term zinc supplementation. Nutrition Research and Practice 2008;2:283-8.

6. Diabetes Control and Complications Trial Research Group. 'The relationship of glycemic exposure $\left(\mathrm{HbA}_{1 \mathrm{C}}\right)$ to the risk of development and progression of retinopathy in the diabetes control and complications trial', Diabetes 1995;44;968.

7. Nathan DM, Singer DE, Hurxthal K, Goodson JD. The clinical information value of the glycosylated hemoglobin assay. N Engl J Med 1984;310:341-6.

8. American Diabetes Association: Standards of medical care in diabetes; Diabetes Care 2010;33(Suppl 1):S13.

9. Akita Abe, Yiamashita S. Clin Chem 1989;35/4:552-4.

10. Tetsuo Makino. Clin Chem Acta 1991;197:209-20.

11. Trivelli LA, RanneyHM, Lai HT. Hemoglobin components in patients with diabetes mellitus. N Engl J Med 1971;284:353-7.

12. Bunn HF. Evaluation of glycosylated hemoglobin in diabetic patients. Diabetes 1981;30:613-17.

13. Trinder P. Glucose oxidase-peroxidase method. Ann Clin Biochem. 1964;6:24

14. Raabo E, Terkildsen TC. On the enzymatic determination of blood glucose. Scand J Clin Lab Invest 1960;12:402-07.

15. Berthelot MP. Berthelot's reaction mechanism. Report Chim Appl 1859;2884.

16. Fawcett JK Scott JE J Chim Pathol 1960;13:156.

17. Bosnes RW, Taussy HH. On the colorimetric determination of creatinine by the Jaffe reaction. J Biol Chem 1945;158:581-91.

18. Toro G, Ackermann PG. Practical Clinical Chemistry. Boston: Little Brown and Co; 1975. p. 154.

19. Kinlaw WB, Levine S, Morley J, Silvis S, McClain C. Abnormal Zn metabolism in type II diabetes mellitus. Am J Med 1983;75:273-7.

20. Zalewski P, Millard S, Forbes I, Kapaniris O, Slavotinek S, Betts W, Ward A, et al. Video image analysis of labile $\mathrm{Zn}$ in viable pancreatic islet cells using specific fluorescent probe for Zn. J Histochem Cytochem 1994;42:877-84.

21. Williams NR, Rajput-Williams J, West J, Nigdikar S, Foote J, Howard A. Plasma, granulocyte and mononuclear cell copper and zinc in patients with diabetes mellitus. Analyst 1995;120:887-90.

22. McNair P, Kiilerich S, Christiansen C, Christiansen M, Madsbad S, Transbol I. Hyperzincuria in insulin treated diabetes mellitus-its relation to glucose homeostasis and insulin administration. Clinica Chimica Acta 1981;112:343-8.

23. Garg V, Gupta R, Goal R. Hypozincemia in diabetes mellitus. J Assoc Physicians India 1994;42:720-1.

24. The Diabetes Control and Complications Trial Research Group. N Engl J Med 1993;329:977-86.

25. Tight blood pressure control and risk of macrovascular and microvascular complications in type 2 diabetes: UKPDS 38 BMJ 1998;317:703.

26. Khaw KT. Glycated haemoglobin, diabetes, and mortality in men in Norfolk cohort of European Prospective Investigation of Cancer and nutrition (EPIC-Norfolk). BMJ 2001;322:15-18.

27. Verma. Effect of Increasing Duration of Diabetes Mellitus Type 2 on Glycated Hemoglobin And Insulin Sensitivity, Indian J Clin Biochem 2006;21:142-6.

28. Refaat A. Al-Maroof, Shatha S. Al-Sharbatti; Serum zinc levels in diabetic patients and effect of zinc supplementation on glycemic control of type 2 diabetics. Saudi Med J 2006;27:344-50.

29. Marchesini G, Bugianesi E, Ronchi M, Flamia R, Thomaseth K, Pacini G. Zinc supplementation improves glucose disposal in patients with cirrhosis. Metabolism 1998;47:792-8.

How to cite this article: Saharia GK, Goswami RK. Evaluation of serum zinc status and glycated hemoglobin of type 2 diabetes mellitus patients in a tertiary care hospital of Assam. J Lab Physicians 2013;5:30-3.

Source of Support: Institute Thesis Grant of Rs 4000/- (Rupees four thousand only) and existing facility at the Department of Biochemistry, Assam Medical College Dibrugarh. Conflict of Interest: None declared. 